\section{Review of Granular Applicators for Turfgrass}

\author{
Richard L. Parish ${ }^{1}$
}

\begin{abstract}
AdDITIONAL INDEX wORDs. spreader, granules, application, granular fertilizer, granular pesticide

SUMMARY. Application of granular materials is an important part of most turfgrass maintenance programs, but is not often studied by horticulturists. Agricultural engineers have conducted many research studies over the past 50 years on the theory, testing, and use of granular applicators. Understanding the theory of granular distribution can aid horticulturists and turfgrass professionals in the effective use of spreaders. This article will review relevant engineering studies and interpret some of the results to provide help in using spreaders more effectively. Proper operating mode, proper pattern adjustment, and the use of an appropriate swath width can greatly improve pattern uniformity. For instance, a half-width pattern has been proven more effective at pattern improvement than right-angle patterns, and the detrimental effect of humidity on spreader pattern has been demonstrated.
\end{abstract}

$\mathrm{I}$ NTRODUCTION AND REVIEW OF THEORETICAL STUDIES. GRANULAR VS. LIQUID APPLICATION. Broadcast applicators (spreaders) are the primary means for applying granular fertilizers, granular pesticides, and seeds to turfgrass. Application procedures are similar, but differences in density, flowability, and response to humidity will affect the results. Liquid application (sprayers) can be used for all of these materials and often is used for commercial applications, but granular application offers advantages. When applying granules, there is no need to haul and apply water; thus no heavy water tank is needed. This one factor alone has led some lawncare service companies to abandon their heavy spray trucks and switch to granular application. Another advantage to granular application is ease of application to lawn and small areas. A broadcast spray boom is easy to use on a large, open area such as a golf course, but is not practical on most lawns and many smaller commercial sites. A major advantage of granular materials is ease of application-particularly for homeowners. It is virtually impossible in most cases

\footnotetext{
Hammond Research Station, Louisiana State University Agricultural Center, 21549 Old Covington Highway, Hammond, LA 70403.

Approved for publication by the Director of the Loui siana Agricultural Experiment Station as manuscript no. 06-53-0129. Use of trade names does not imply endorsement by the LSU AgCenter of products named nor criticism of similar ones not named.

${ }^{1}$ To whom reprint requests should be addressed. E-mail address: dparish@agcenter.lsu.edu
}

to tell a homeowner how to apply a recommended rate of liquid product, but granular products typically carry spreader setting recommendations on the bag label. The liquid application equipment commonly available to homeowners leaves both swath width and rate at the discretion of the user. Most liquid product labels merely give the desired rate in some units such as fluid ounces per $1000 \mathrm{ft}^{2}$ without any information on how to obtain this rate. This article will review relevant engineering studies and interpret some of the results to provide help in using spreaders more effectively.

ENGINEERING STUDIES ON THE DYNAMICS OF GRANULAR APPLICATION. Although granular applicators are common, too often they are not understood by the people using them. There is a large body of research on granular application. Some of this work is theoretical and aimed at helping engineers better understand and model granule behavior during application. Other work is more applied and offers insight to spreader users on practices to improve the quality of application.

Studies of the physics of granule movement on impellers and granule trajectory have allowed engineers to develop computer models of granule paths and granule trajectory (Brinsfield and Hummel, 1975; Crowther, 1958; Cunningham and Chao, 1967; Davis and Rice, 1974; Griffis et al., 1983; Grift, 2000; Grift and Hofstee, 2002; Grift et al., 2000; Hepard and Pascal, 1958; Inns and Reece, 1963; Law and Collier, 1973; Mennel and Reece, 1963; Patterson and Reece, 1962; Pitt et al., 1982; Reed and Wacker, 1970). These studies have demonstrated the complexity of the problem. It is relatively straightforward to model the behavior of a single spherical granule, but it is extremely difficult to predict the distribution pattern from odd-shaped granules in a range of sizes dropped onto a relatively large area of a spreader impeller. No models are currently available that are of value to horticulturists or turf professionals.

EMPIRICAL STUDY OF PARTICLE BEHAVIOR. Griffis et al. (1983), as an unpublished part of their study, used high-speed photography to study the motion of granules. They noted that: 1) granules slide, not roll along the impeller fins; 2) granules leave the impeller at an angle that is approximately $10^{\circ}$ to $15^{\circ}$ from a line tangent to the rim of the impeller; and 3) some granules tend to bounce over the fins.

Pattern testing PROCedures. Testing of granular applicator patterns is standardized by American Society of Agricultural Engineers (ASAE) S341.3, Procedure for measuring distribution uniformity and calibrating granular broadcast spreaders (ASAE, 2005). This standard defines a procedure for conducting spreader pattern tests using a row of collection trays perpendicular to the line of travel. The configuration of the trays is specified, as is the method of reporting the results. This standard is the result of many research studies conducted by agricultural engineers over the years (Broder, 1983; Cunningham, 1963; DeBoer and Wiens, 1983; Drever and Wiens, 1979; Glover and Baird, 1973; Parish, 1986a, 1996, 1999a, 2003a).

Several research studies have examined the effect of test method and have demonstrated that the use of hard (e.g., steel or plastic) collection trays on a paved surface does not necessarily result in the same pattern as obtained

\begin{tabular}{llll}
\hline $\begin{array}{l}\text { Units } \\
\begin{array}{l}\text { To convert U.S. to SI, } \\
\text { multiply by }\end{array}\end{array}$ & U.S. unit & SI unit & $\begin{array}{l}\text { To convert SI to U.S., } \\
\text { multiply by }\end{array}$ \\
\hline 3.1833 & $\mathrm{fl} \mathrm{oz} / 1000 \mathrm{ft}^{2}$ & $\mathrm{~L} \cdot \mathrm{ha}^{-1}$ & 0.3141 \\
1.6093 & $\mathrm{mph}$ & $\mathrm{km} \cdot \mathrm{h}^{-1}$ & 0.6214
\end{tabular}


when a spreader is used on turfgrass due to granules bouncing out of the trays or into the trays from the hard base surface (Parish, 199la, 1996; Parish and Porter, 1994; Parish et al., 1987; Whitney et al., 1987). Even though ASAE S341.3 requires the use of collection trays with subdivisions to reduce granule bounce-out, bounce-in can still occur. The standard does not address this problem.

A computer program, SPREADER.EZ, has been developed to facilitate analysis of spreader pattern data (Parish, 1987a). This program allows a user to input spreader pattern test data and obtain information on overlapped patterns using a range of swath widths. From this information, a user can determine whether a pattern is acceptable and what the effective swath width should be.

Effective swath width should be chosen to optimize both width and uniformity (Parish, 1999b). Coefficient of variation $(\mathrm{CV})$ and pattern extremes (lowest and highest points in the overlapped pattern should both be considered. A CV $\leq 10 \%$ is desirable, but a goal of $\mathrm{CV} \leq 20 \%$ is probably more realistic and $\leq 30 \%$ may be appropriate for insecticides since insects are mobile and uniformity is less important. A range of $80 \%$ to $120 \%$ of mean is a good goal for the pattern extremes (70\% to 130\% for insecticides). When CV is plotted as a function of swath width, it is common to find two minimum points in the curve. Sometimes the minimum at the greater swath width (sometimes called the "normal swath width") will give adequate uniformity; in other cases, the smaller width will be necessary to achieve adequate uniformity. In some cases, if the pattern is skewed, neither width will give adequate uniformity. Some people have suggested that a swath width of half the overall throw width should be used, but this is seldom the optimum effective width.

It is normally necessary to conduct pattern tests on broadcast spreaders to 1) allow optimum pattern adjustment to provide a centered pattern and 2) to determine the effective swath width (i.e., the distance from the center of one spreader pass to the center of the adjacent pass). Once an effective swath width has been determined (Parish, 1987a, 1999b, 2000a), an appropriate rate setting can be determined. It is possible to determine the delivery rate from the pattern test data, but this has been shown to provide inaccurate results due to granule bounce into and out of the collection trays (Parish, $2000 b, 2002 a)$. Conducting separate rate setting tests is more accurate and is the recommended method (Parish, 1999b). For walk-behind spreaders, the preferred method of conducting rate tests is to run the spreader on a test stand that rotates the spreader drive tire at a peripheral speed equal to the desired ground speed $(2.75 \mathrm{mph}$ for homeowner spreaders and $3.0 \mathrm{mph}$ for professional spreaders) while the material falling from the spreader is collected in a catch pan (Parish, 1999b). When rotary broadcast spreaders are used on a test stand, either the impeller must be removed or the impeller must be shrouded so that the material falls into the catch pan.

Many of the spreader settings found on granular product labels were developed by the author at the Hammond Research Station-Louisiana State University Agricultural Center. Many granular product companies do not have the facilities or expertise to develop spreader settings themselves and contract with us for this work.

ROTARY SPREADER FUNDAMENTALS. Since granules leave the impeller at an angle that is nearly tangential (Fig. 1), skewing is inherent in any single-impeller rotary spreader.

Figure 2 shows how a band of granules typically leaves an impeller and demonstrates the inherent skewing with a rotary spreader.

Typical metering ports found on rotary spreaders are a single crescentshaped port and a cluster of three circular ports. A cluster of three ports will generally allow a wider pattern with acceptable uniformity. Several methods are used on different spreaders to provide a means of pattern correction. The most effective methods shift the complete pattern from side to side. This can be accomplished by rotating the discharge ports about the impeller axis (Parish and Chaney, 1986b) or by moving the discharge ports radially on the impeller (Parish, 1991b; Parish and Chaney, 1985). Another method of spreader pattern correction is the partial or full closure of one or two ports (Parish, 2003b). This method merely reduces the throw to one side rather than shifting the entire pattern.

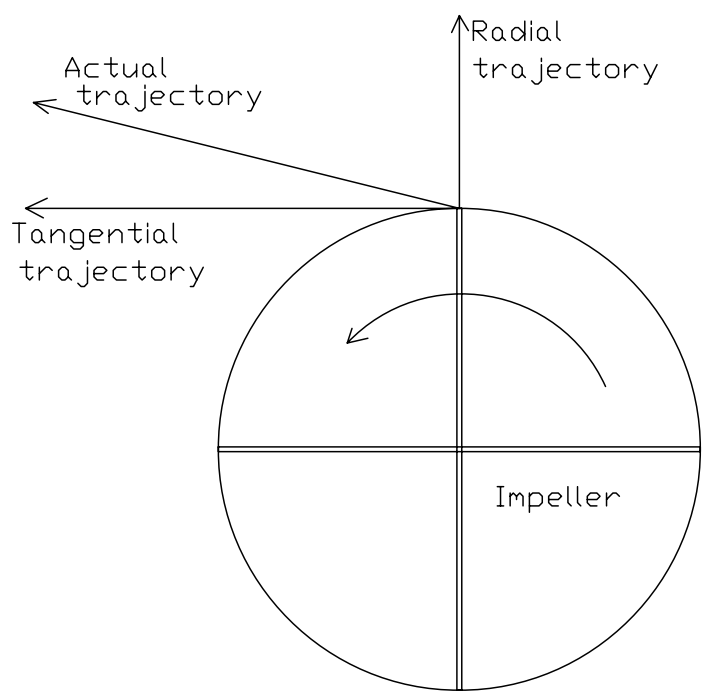

Fig. 1. Typical trajectory from rotary spreader.

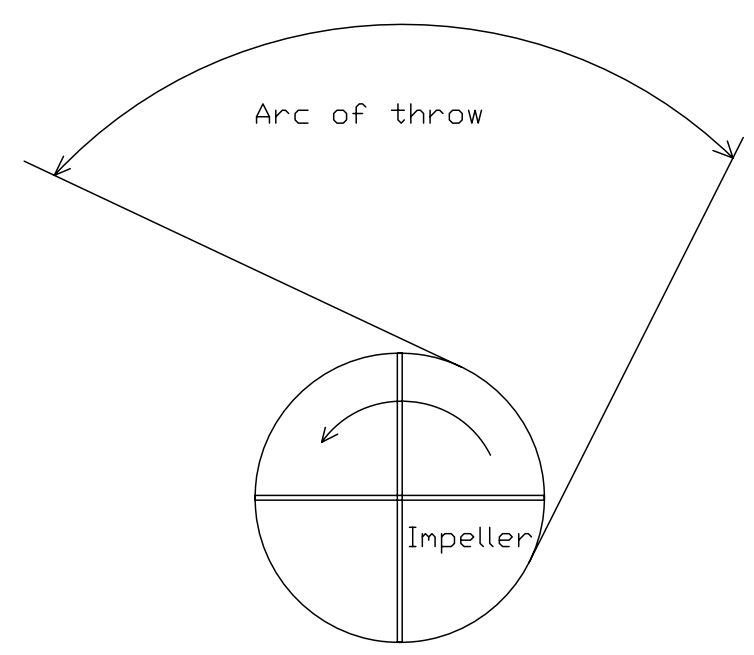

Fig. 2. Typical skewed pattern inherent with a rotary spreader. 
Regardless of which method is used on pattern tests be conducted and the results used to correct the pattern until the best possible pattern is obtained.

SPREAdER OPERATING MODE. Spreaders can be operated in a circuitous mode (operating around an area in a spiral manner) or a continuous mode (adjacent back-and-forth passes) (Parish, 1990). The continuous mode is more common, but results in the right side of the pattern being overlapped on the right side of the adjacent pass and the left side of the pattern overlapped on the left side of the adjacent pass. This exaggerates any skewing that might be present in the base pattern. Circuitous patterns cause uneven application at the corners, but overlap left side on right side and right side on left side, thus tending to cancel out some of the effects of skewing. Most turf applications are made using the continuous mode and thus recommended swath widths are based on a continuous mode.

Some spreader recommendations in the past have suggested that operators use a half-rate setting and make two trips over the area at right angles as a means of improving uniformity. This procedure has been demonstrated to be considerably less effective than making only one trip using a half-rate setting and half the effective width when pattern improvement is necessary (Parish, 1986b). In most cases, this half-width method will not be necessary, but if a satisfactory pattern cannot be achieved with a normal width or if application uniformity is critical, the half-width method should always be used instead of the right-angle method. The rightangle method is never appropriate.

SPREADER SPEED. As stated earlier, standardized speeds are used to allow spreader setting recommendations on product labels. In addition to the walk-behind speeds quoted, tractormounted or tractor-drawn turf spreaders are usually operated at $4.5 \mathrm{mph}$. Speed affects both rate and pattern (Parish, 1987b; Parish and Chaney, ting, increasing the ground speed will decrease the application rate to some extent. With most rotary spreaders, metering is gravimetric (i.e., the rate per minute is constant, regardless of speed) so the change in rate will be linearly related to speed. With a droptype spreader, the effect of speed is a given spreader, it is important that 1986a). With a given spreader rate set- somewhat less pronounced, but turf drop spreaders are not volumetric; speed does have an effect on rate. With rotary spreaders pattern is also affected by speed. On walk-behind and tractor-drawn spreaders, the impeller is ground-driven. If the ground speed changes, the impeller speed changes, and this changes the spreader pattern. Not only is the width affected, but also the skewing. Obviously, a spreader can be calibrated (pattern and rate) for any reasonable speed, but it is important to maintain a speed that is consistent and matches the calibration speed.

Effect of Humidity. Most granular fertilizer products have a critical relative humidity (CRH). Some fertilizers are much more hygroscopic than others: $\mathrm{CRH}$ values of fertilizers range from $18 \% \mathrm{RH}$ to $90 \%$. When the humidity is above that point, the fertilizer begins to get sticky. When using a spreader under conditions where the critical relative humidity of the product is exceeded, the granules may absorb moisture, become sticky, and allow material to build up on the impeller. This changes the coefficient of friction of the granules sliding on the impeller and generally slows the granules down, thus causing them to leave the impeller further around the rotation. With the typical counterclockwise impeller rotation (as viewed from above), this means that the pattern will gradually shift to the left as running in high humidity continues (Parish 1991c). Rate and swath width can also be affected. It is important to keep the impeller as clean as possible and adjust the pattern if running under humid conditions.

EFFECTS OF HOPPER/IMPELLER ANGLE. It is very important to maintain a spreader in a level position. This
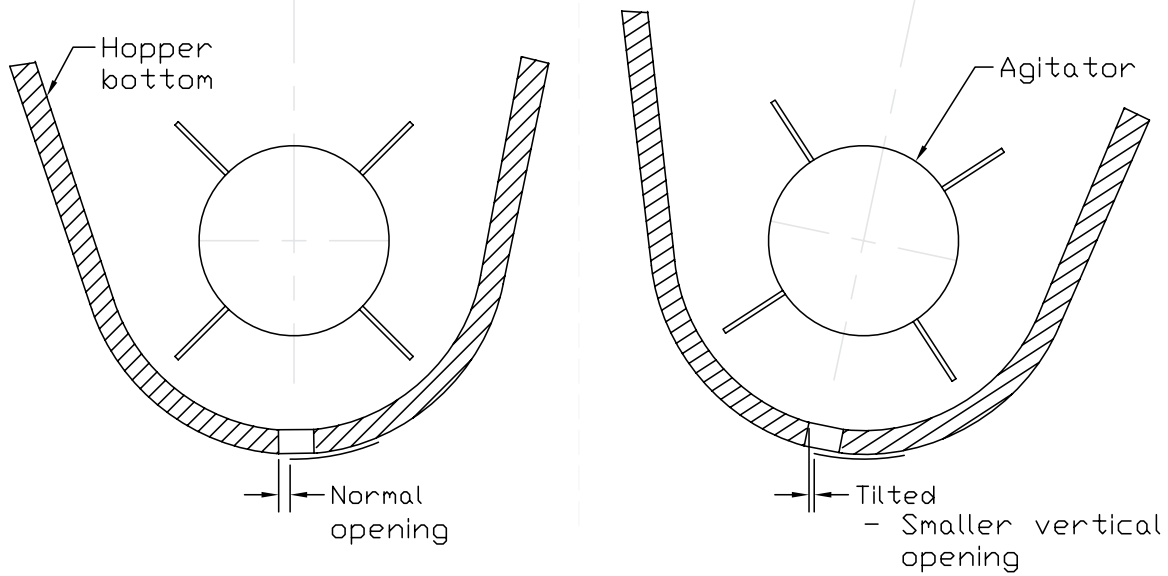

Fig. 3. Effect of hopper angle on opening of port with thick plastic hopper.

can be difficult to do with different operators. Tall operators tend to hold the handle higher and thus tilt the spreader forward while short operators tend to hold the handle lower and tilt the spreader back. If the impeller on a rotary spreader is not level, the width and pattern can be changed (Parish, 2003c). Maintaining the correct angle (i.e., handle height) is also important with drop spreaders. As shown in Figure 3, changing the angle of a typical plastic drop spreader changes the effective vertical opening of the ports. Lowering the handle decreases the vertical opening, thus decreasing the delivery rate. This can have a profound effect on delivery rate (Parish, 1999c).

OTHER FACTORS AFFECTING RATE AND PATTERN. Many factors can affect the distribution from a rotary spreader. A rough operating surface can distort the pattern (Parish, 1991d). Pulling a spreader backwards can make a major change in rotary spreader pattern and can affect the rate from a drop spreader (Parish, 1999d). It is tempting to pull a spreader backwards when operating on loose or soft soil, as when seeding, since much less effort will be required; however, the rate will be different will probably be very distorted with a rotary. Never pull a spreader backwards unless specific rate and pattern recommendations are provided for this mode of operation.

The level of material in the hopper can affect spreader delivery rate (Parish, 1999e). If the agitator is exposed on a drop spreader or the level gets below approximately $10 \%$ on a rotary spreader, the rate may change.

Testing has shown that many with a drop spreader and the pattern 
homeowner rotary spreaders do not deliver an acceptable pattern (Parish, 200la). Most homeowner rotary spreaders do not offer pattern adjustment; thus the patterns from a given spreader change with product. If the spreader is designed to deliver a good, centered pattern with a mid-range product, then the patterns with lighter and heavier products can be marginally acceptable. All true professional rotary spreaders do offer pattern adjustment (Parish, 1999b, 2003b; Parish and Chaney, 1985). It is critical that these pattern adjustments be used effectively to achieve centered patterns.

With tractor-mounted rotary spreaders, it is important to maintain the correct power take-off (PTO) speed (usually $540 \mathrm{rpm}$ ) and impeller height (Parish, 2002b). Changing PTO speed can change the pattern width and also cause pattern skewing. Changing impeller height primarily affects swath width.

In recent years, the major manufacturers of walk-behind professional rotary spreaders have introduced new models that appear to be functionally identical to earlier models, but have a higher impeller drive gear ratio. Testing has shown that the change in impeller drive ratio makes a significant change in distribution pattern (Parish, 2005). A higher drive ratio (with the same size tires) increases impeller speed. This has the dual effects of throwing granules farther and sooner (less angle from drop point to discharge). It is thus necessary to calibrate separately for the different drive ratios and use different pattern settings and, sometimes, widths.

Another factor to consider with spreaders is the size of the rate increments. Ideally, a spreader should be capable of delivering fairly narrow rate increments so that an operator can select an appropriate rate with minimal error. If the rate settings are too large, an operator could potentially be faced with a choice between a setting that delivers a $50 \%$ rate or the next setting that delivers a $150 \%$ rate. Rate increments of $10 \%$ or less are ideal; some homeowner and semiprofessional spreaders have increments of $50 \%$ to $100 \%$ at low rate settings (Parish, 2003d).

USE OF CONTROLLED-RELEASE ENCAPSUlated FerTiLIzer. Controlledrelease fertilizers that use encapsulation of soluble fertilizer granules as the means of controlling release are susceptible to physical damage from spreaders. Both the agitator and the impeller can potentially damage the granule coating, resulting in accelerated release of nutrients. Testing has shown that this potential problem is seldom significant (Parish, 200lb, 2001c).

One-sided Patterns. Since the pattern from broadcast spreaders tapers out from the center, there is a problem when attempting to make a uniform application next to a non-turf area such as a driveway or flower bed. If you keep the spreader far enough to avoid throwing granules onto the nonturf area, the adjacent turf will receive an under-application. If, however, you operate right next to the non-turf area so as to give all the turf a uniform rate, you will throw granules onto the nonturf area. This can be a problem with any product, but is especially serious with granular herbicides. Some spreaders now have a means of addressing this problem. Two approaches are used-usually together. One port (of three) is completely closed to eliminate most throw to one side (typically the left port is closed to eliminate throw to the right on spreaders with a counterclockwise impeller) and also a deflector is lowered (on the right side for the example used here) to completely eliminate throw in that direction. The use of both methods together is effective at providing a sharply delineated pattern but may cause somewhat heavy application right at the demarcation (Parish, 2000c, 2003e). This system can be found on both professional and homeowner spreaders.

SHROUDED SPREADERS. A shroud or skirt around a rotary spreader impeller can help control the distribution

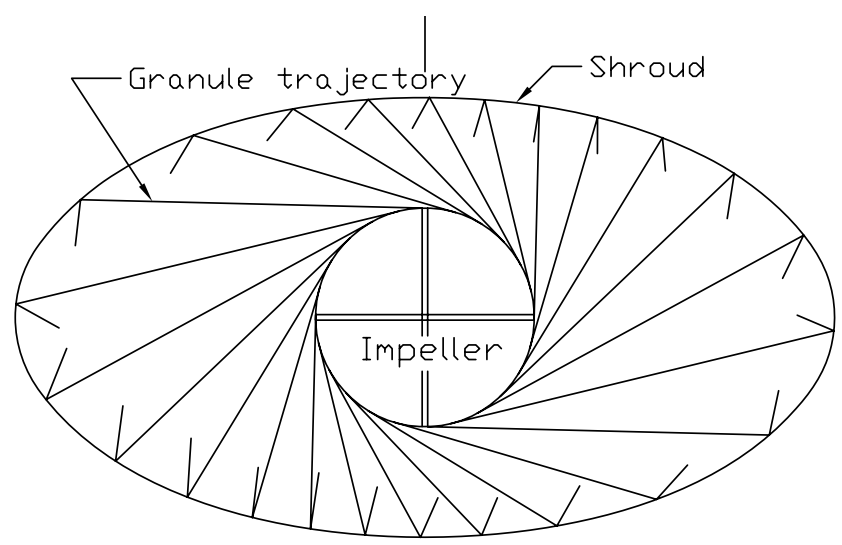

Fig. 4. Principle of a rotary spreader with elliptical shroud. Note that the resulting pattern is heavy toward the center of the pattern and tapers off toward the edges. pattern. A shroud that is elliptical and tapered can provide an excellent trapezoidal pattern (Amerine, 1977; Amerine and Parish, 1979). When a shroud is used, material can be discharged from the spreader in a full $360^{\circ}$ arc, thus eliminating skewing (Fig. 4).

The shroud can be designed to limit the pattern to a width that corresponds with the lightest product anticipated, thus providing a uniform swath width for all products. Only one model of spreader incorporating this concept has gone into commercial production, and it was not successful due to other design problems (Parish, 2000d).

Pendulum-action spreaders. A viable alternative to rotary spreaders in tractor-mounted applications is the pendulum-action spreader. These spreaders have a tube sticking out the rear that oscillates in a horizontal plane about the centerline of the spreader, slinging granules from side to side. Granules are metered into the oscillating tube through ports in the hopper bottom. These spreaders have a major advantage over rotary spreaders in that their patterns are inherently centered, not skewed (Parish, 1995a, 2001d; Parish and Bergeron, 1991). It is still necessary to conduct a single pattern test with each product to determine the effective swath width (Parish, 1995b). Rate calibration is easily done on pendulum spreaders by removing the spout and catching the material during a timed stationary run.

SUGGESTIONS FOR FUTURE WORK. Continued theoretical research on granular applicator trajectories may lead to effective predictions of patterns. The ability to predict pattern uniformi- 
ty and swath width for a given spreader and product combination without pattern testing would be a great boon to the industry. Unfortunately, this goal is many years away. Applied research on new spreader concepts should continue as manufacturers introduce them. There is a continuing need for independent research to evaluate spreader technology and provide guidance to horticulturists and turf professionals on use of granular applicators.

\section{Literature cited}

American Society of Agricultural Engineers. 2005. American Society of Agricultural Engineers standards. S341.3 FEB04: Procedure for measuring distribution uniformity and calibrating granular broadcast spreaders. Amer. Soc. Agr. Eng., St. Joseph, Mich.

Amerine, J.D. 1977. Material spreader. U.S. Patent number 4032074. U.S. Patent and Trademark Office, Washington, D.C.

Amerine, J.D. and R.L. Parish. 1979. Development of a rotary spreader with elliptical shroud. Amer. Soc. Agr. Eng. Paper No. 79-1511.

Brinsfield, R.B. and J.W. Hummel. 1975. Simulation of a new centrifugal distributor design. Trans. Amer. Soc. Agr. Eng. 18(2):213-220.

Broder, M.F. 1983. Performance testing of fertilizer application equipment. Amer. Soc. Agr. Eng. Paper No. 83-1503.

Crowther, A.J. 1958. Distribution of particles by a spinning disc. J. Agr. Eng. Res. 3(4):288-291.

Cunningham, F.M. 1963. Performance characteristics of bulk distributors for granular fertilizers. Trans. Amer. Soc. Agr. Eng. 6(2):108-114.

Cunningham, F.M. and E.Y.S. Chao. 1967. Design relationships for centrifugal fertilizer distributors. Trans. Amer. Soc. Agr. Eng. 10(1):91-95.

Davis, J.B. and C.E. Rice. 1974. Predicting fertilizer distribution by a centrifugal distributor using CSMP, a simulation language. Trans. Amer. Soc. Agr. Eng. 17(6):1091-1093.

DeBoer, L.J. and E.H. Wiens. 1983. Test procedure for granular applicator performance testing. Amer. Soc. Agr. Eng. Paper No. 83-1504.

Drever, K.W. and E.H. Wiens. 1979. Granular herbicide applicator testing. Amer. Soc. Agr. Eng./Can. Soc. Agr. Eng. Paper No. 79-1006.
Glover, J.W. and J.V. Baird. 1973. Performance of spinner type fertilizer spreaders. Trans. Amer. Soc. Agr. Eng. $16(1): 48-51$.

Griffis, C.L., D.W. Ritter, and E.J. Matthews. 1983. Simulation of rotary spreader distribution patterns. Trans. Amer. Soc. Agr. Eng. 26(1):33-37.

Grift, T.E. 2000. Spread pattern analysis tool (SPAT): I. Development and theoretical examples. Trans. Amer. Soc. Agr. Eng. 43(6):1341-1350.

Grift, T.E. and J.W. Hofstee. 2002. Testing an online spread pattern determination sensor on a broadcast fertilizer spreader. Trans. Amer. Soc. Agr. Eng. 45(3): 561-567.

Grift, T.E., J.T. Walker, and D.R. Gardisser. 2000. Spread pattern analysis tool (SPAT): II. Examples of aircraft pattern analysis. Trans. Amer. Soc. Agr. Eng. 43(6):1351-1362.

Hepard, R.Q. and J.A. Pascal. 1958. The transverse distribution of fertilizer by conventional types of distributors. J. Agr. Eng. Res. 3(2):95-107.

Inns, F.M. and A.R. Reece. 1963. The theory of the centrifugal distributor II: motion on the disc, off-center feed. J. Agr. Eng. Res. 7(4):345-353.

Law, S.E. and J.A. Collier. 1973. Aerodynamic resistance coefficients of agricultural particulates determined by elutriation. Trans. Amer. Soc. Agr. Eng. 16(5):918-921.

Mennel, R.M. and A.R. Reece. 1963. The theory of the centrifugal distributor III: particle trajectories. J. Agr. Eng. Res. 8(1):78-84.

Parish, R.L. 1986a. Comparison of spreader pattern evaluation methods. Appl. Eng. Agr. 2(2):89-93.

Parish, R.L. 1986b. Evaluation of two methods of fertilizer spreader pattern correction. Trans. Amer. Soc. Agr. Eng. 29(2):370-373.

Parish, R.L. 1987a. A computer program for spreader pattern analysis. Appl. Eng. Agr. 3(1):14-16.

Parish, R.L. 1987b. The effect of speed on performance of a rotary spreader. Appl. Eng. Agr. 3(1):17-19.

Parish, R.L. 1990. Spreader pattern as influenced by operating mode. Appl. Eng. Agr. 6(6):687-690.

Parish, R.L. 1991a. Effect of material bouncing into and out of collection pans on observed spreader distribution pattern. Appl. Eng. Agr. 7(3):311-315.
Parish, R.L. 1991b. Effect of an adjustable drop point on turf fertilizer spreader patterns. Appl. Eng. Agr. 7(1):5-9.

Parish, R.L. 1991c. The effect of relative humidity on rotary turf spreader patterns. Appl. Eng. Agr. 7(5):541-544.

Parish, R.L. 1991d. Effect of rough operating surface on rotary spreader distribution pattern. App. Eng. Agr. 7(1):61-63.

Parish, R.L. 1995a. Pattern skewing with a pendulum spreader. Appl. Eng. Agr. $11(4): 511-512$.

Parish, R.L. 1995b. Estimating effective swath width with a pendulum spreader. Appl. Eng. Agr. 11(4):507-509.

Parish, R.L. 1996. Particle size effects on collection efficiency across spreader pattern tests. Appl. Eng. Agr. 12(5):527-529.

Parish, R.L. 1999a. The effect of multiple passes on spreader pattern test results. Appl. Eng. Agr. 15(6):643-645.

Parish, R.L. 1999b. Granular spreaders: Selection, calibration, testing, and use. La. Agr. Expt. Sta. Bul. 866.

Parish, R.L. 1999c. Effect of hopper angle on drop spreader delivery rate. App. Eng. Agr. 15(4):279-281.

Parish, R.L. 1999d. Effect on delivery rate of pulling a drop spreader backward. Appl. Eng. Agr. 15(5):429-430.

Parish, R.L. 1999e. The effect of spreader fill level on delivery rate. Appl. Eng. Agr. 15(6):647-648.

Parish, R.L. 2000a. Ramifications of method of selecting effective swath width. Appl. Eng. Agr. 16(5):493-495.

Parish, R.L. 2000b. Spreader rate determinations from pattern tests compared with rate calibration. Appl. Eng. Agr. 16(2):119-120.

Parish, R.L. 2000c. Evaluation of one-sided throw controls on walk-behind turf spreaders. Appl. Eng. Agr. 16(4):387-390.

Parish, R.L. 2000d. Evaluation of a lawn spreader with an elliptical shroud. Appl. Eng. Agr. 16(2):115-117.

Parish, R.L. 200la. Pattern uniformity with homeowner rotary spreaders. Appl. Eng. Agr. 17(2):127-130.

Parish, R.L. 2001b. Spreader damage to encapsulated controlled-release fertilizer granules. Appl. Eng. Agr. 17(4):457458 .

Parish, R.L. 2001c. Effect of coating thickness on spreader damage to encapsulated controlled-release fertilizer granules. Appl. Eng. Agr. 17(4):459-460. 
Parish, R.L. 2001d. The effects of spout height and PTO speed on banding with a pendulum-action spreader. Appl. Eng. Agr. 17(6):765-766.

Parish, R.L. 2002a. Rate setting effects on fertilizer spreader distribution patterns. Appl. Eng. Agr. 18(3):301-304.

Parish, R.L. 2002b. Broadcast spreader pattern sensitivity to impeller/spout height and PTO speed. Appl. Eng. Agr. 18(3):297-299.

Parish, R.L. 2003a. Comparison of ASAE S341.3 spreader pattern testing with stationary spreader pattern tests. Appl. Eng. Agr. 19(6):645-648.

Parish, R.L. 2003b. Comparison of pattern adjustment methods on professional rotary turf spreaders. Appl. Eng. Agr. 19(5):535-537.

Parish, R.L. 2003c. Effect of impeller angle on pattern uniformity. Appl. Eng. Agr. 19(5):531-533.

Parish, R.L. 2003d. Turf spreader rate setting increments. Appl. Eng. Agr. 19(2):155-157.
Parish, R.L. 2003e. Evaluation of a homeowner rotary spreader with deflector to close one side of the pattern. Appl. Eng. Agr. 19(6):641-643.

Parish, R.L. 2005. The effect of impeller drive gear ratio on rotary spreader patterns. Appl. Eng. Agr. 21(6):987-989.

Parish, R.L. and P.E. Bergeron. 1991. Field and laboratory study of a pendulum-action spreader. Appl. Eng. Agr. 7(2):163-167.

Parish, R.L. and P.P. Chaney. 1985. Evaluation of a rotary spreader with a helical cone for drop point control. Trans. Amer. Soc. Agr. Eng. 28(5):1440-1444.

Parish, R.L. and P.P. Chaney. 1986a. Speed effects on drop-type spreader application rate. Appl. Engr. Agr. 2(2):94-96.

Parish, R.L. and P.P. Chaney. 1986b. Pattern sensitivity to location of fertilizer drop point on a rotary spreader impeller. Trans. Amer. Soc. Agr. Eng. 29(2):374-377.

Parish, R.L., P.P. Chaney, and D.L. Fuller. 1987. Comparison of laboratory methods of spreader pattern evaluation with agronomic response. Appl. Engr. Agr. $3(2): 237-240$.
Parish, R.L. and W.C. Porter. 1994. Spreader patterns using ASAE S341.2 compared to patterns in golf-cup sized holes in turfgrass. Appl. Engr. Agr. 10(6):783-786.

Patterson, D.E. and A.R. Reece. 1962. The theory of the centrifugal distributor I: Motion on the disc, near-center feed. J. Agr. Engr. Res. 7(3):232-240.

Pitt, R.E., G.S. Farmer, and L.P. Walker. 1982. Approximating equations for rotary distributor spread patterns. Trans. Amer. Soc. Agr. Eng. 25(6):1544-1552.

Reed, W.B. and E. Wacker. 1970. Determining distribution pattern of dry fertilizer applicators. Trans. Amer. Soc. Agr. Eng. 13(1):85-89.

Whitney, R.W., L.O. Roth, and D.K. Kuhlman. 1987. Performance of selected granular collectors. Trans. Amer. Soc. Agr. Eng. 30(2): 338-342. 